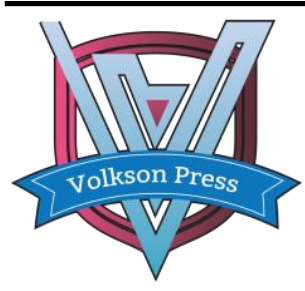

Contents List available at VOLKSON PRESS

Engineering \& Technology Innovations (ETI)

DOI : http://doi.org/10.26480/iceti.01.2017.90.93

\title{
A MODEL FOR SIMULATING THE SPRING FLOW AND GROUNDWATER LEVEL IN A DEPLETED KARST AQUIFER - A CASE STUDY OF THE JINCI SPRING
}

\author{
Yuqiao Long1, ${ }^{1,}$, Tingting Cui ${ }^{1,2}$, Wei Li1, 2, Zhongping Yang ${ }^{3}$, Yongwei Gai ${ }^{4}$ \\ 1. Nanjing Hydraulic Research Institute, Nanjing, China; \\ 2. State Key Laboratory of Hydrology-Water Resources and Hydraulic Engineering, Nanjing, China; \\ 3. College of civil engineering, Chongqing University, Chongqing, China; \\ 4. Water Resources Service Center of Jiangsu Province, Nanjing, China
}

This is an open access article distributed under the Creative Commons Attribution License, which permits unrestricted use, distribution, and reproduction in any medium, provided the original work is properly cited

\section{ARTICLE DETAILS}

\section{Article History:}

Received 02 october 2017

Accepted 06 october 2017

Available online 11 october 2017

Keywords:

reservoir model; karst aquifer; groundwater; depletion; Jinci Spring.

\section{ABSTRACT}

A reservoir model is developed to characterize the functioning of the karst aquifer of the Jinci Spring. It is based on the relationship of the groundwater storage deficit and the groundwater level. The relationship is derived from the monitoring data of the aquifer. The model is verified with the monitoring data (1981-2006). The results show that the reservoir model can describe the character of karst development and the heterogeneity in vertical direction. The model takes account of the artificial recharge, pumping and coal mine drainage, and can simulate the spring discharge, karst groundwater level and the storage deficit accurately at an annual time scale. The model is suitable for macroscopic groundwater management.

\section{INTRODUCTION}

At present, China has 164 groundwater overexploitation zones of which the total area is about $181291 \mathrm{~km}^{2}$ [1]. The karst groundwater overexploitation zones with a total area about $7393 \mathrm{~km}^{2}$ mainly locate in the Liao River Basin $\left(1941 \mathrm{~km}^{2}\right)$, the Yellow River Basin $\left(4216 \mathrm{~km}^{2}\right)$ and the Huai River Basin (1144 $\mathrm{km}^{2}$ ) [1]. Long term overexploitation leads to the depletion of the karst aquifers in some parts of Shanxi Province and Shandong Province (they locate in the Yellow River Basin), where some famous springs (Jinci Spring, Lan Spring, Nangziguang Spring and Baotu Spring) dry up. It is concerned about the time span and the exploitation schemes to recover the groundwater level and spring flows in these districts, so the model for karst aquifer management is needed to answer these questions.

Long term depletion-type extraction of groundwater in a karst aquifer provides the reservoir model required data with which the reservoir model can resemble the karst aquifer in a better way. Under a depletion status, the discharge of the karst groundwater exceeds its recharge, the storage is consumed continuously, and the karst groundwater level drops gradually. So the storage and the relationship of the storage and the groundwater level can be derived from the monitoring data. The change of storage reflects the change of the volume of the karst voids which can yield water, and exemplifies the heterogeneity of the karst aquifer in the vertical direction. A better similarity between the karst aquifer and the reservoir model can be obtained, if we take the groundwater storage as the reservoir volume.

This paper is aimed at predicting the recovery of spring flows and karst groundwater level in the Jinci Spring basin. A reservoir model is built to characterize the functioning of the karst aquifer of the Jinci Spring based on the data of recharge, discharge and groundwater level during the long term depletion-type extraction. The model has three inlets (rainfall infiltration, river seepage and artificial recharge) and five outlets (well withdrawal, coal mine drainage, Jinci Spring, Xuan spring and lateral discharge). The discharge, the recharge and the deficit (or storage variation) compose a water balance equation which is a nonlinear equation with a single variable and is solved by the bisection method. The model is verified with the monitoring data.

\section{Method}

\subsection{Reservoir model and water balance equation}

A reservoir model is built to characterize the functioning of the karst aquifer of the Jinci Spring. The model has three inlets (rainfall infiltration, river seepage and artificial recharge) and five outlets (well withdrawal, coal mine drainage, Jinci Spring, Xuan spring and lateral discharge) (Figure 1). The artificial recharge, the well withdrawal and the coal mine drainage can be controlled by exploitation schemes, while the spring flow and the lateral discharge are the unknown variables to be evaluated by the model.

The volume of reservoir is defined as the volume of groundwater yielded from the karst aquifer between the highest groundwater level and the lowest groundwater level during the monitoring time span. The empty volume of the reservoir at the time point $t$ is the deficit at the same time point, noted as $Q^{t}$. The groundwater level is highest and the deficit is zero at the beginning of the monitoring time span, the groundwater level is lowest and the deficit reaches the maximum (the reservoir volume) at the end of the monitoring time span, when a karst aquifer is depleting. The difference of the discharge and recharge at the time point $t$ is the variation of deficit at the time point $t$, noted as $\Delta Q^{t}$. We have

$$
Q^{t}=\sum_{i=1}^{t} \Delta Q^{i}
$$

The $\Delta Q^{t}$ can be expressed as the difference between deficit at the time point $t$ and the deficit at the time point $t-1$. Hence, we have

$$
\Delta Q^{t}=Q^{t}-Q^{t-1}
$$

The water balance equation of karst aquier of Jinci Spring is

$$
Q^{t_{11}}+Q^{t_{12}}+Q^{t_{13}-}\left(Q^{t_{01}+Q^{t}}{ }_{02}+Q^{t}{ }{ }^{3}+Q^{t} 04+Q^{t} 05\right)=\Delta Q^{t}
$$

Where $Q^{t_{11}} Q^{t}{ }_{12}$ and $Q^{t}{ }_{13}$ represent the rainfall infiltration, the Fen River leakage and the artificial recharge at the time point $t, Q^{t}{ }_{01}, Q^{t}{ }_{02}, Q^{t}{ }_{03}, Q^{t} 04$ and $Q^{t} 05$ are the well withdrawal, coal mine drainage, Jinci Spring flow, Xuan Spring flow and lateral discharge at the time point $t$, and $\Delta Q^{t}$ is the 
variation of deficit at the time point $t$.

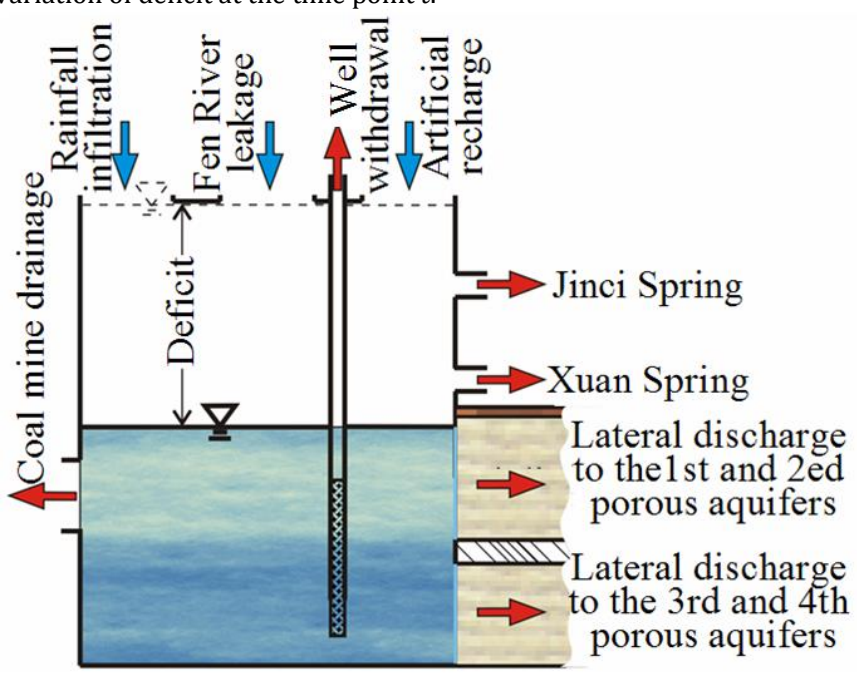

Figure 1 General architecture of the reservoir model

\subsection{Deficit and karst groundwater level}

When a karst aquifer is depleting, $h^{t}$, the groundwater level at the time point $t$, equals the difference of the $h^{t-1}$, the groundwater level at time point $t-1$, and $\Delta h^{t}$, the groundwater level variation at the time point $t$, i.e. $h^{t}=h^{t-1}$ $\Delta h^{t}$. The quotient of $\Delta Q^{t}$ divided by $\Delta h^{t}$ is the average area of the karst voids yielding water between $h^{t}$ and $h^{t-1}$, noted as $A^{t-1}$.

The variation of deficit could be rewritten as $\Delta Q^{t}=\left(h^{t-1}-h^{t}\right) \cdot A^{t-1}$. Here, we suppose that the variation of deficit between each two adjacent monitoring time point could be described as a linear function of the karst groundwater level. So the $\Delta Q^{j}$ could written as $\Delta Q^{j} \approx\left(h^{t-1}-h^{t}\right) \cdot A^{t-1}$, when $h^{j}$ falls in $\left[h^{t-1}, h^{t}\right]$.

According to equation (1), $Q^{j}$, the deficit at the time point $j(j \in[t-1, t))$, could be expressed as $Q \approx\left(h^{1}-h^{2}\right) \cdot A^{1}+\left(h^{t-1}-h^{\prime}\right) \cdot A^{t-1}$. Where $h^{j}$ is the independent variable, $Q^{j}$ is the dependent variable, and the others are constants which could be represented by $C$. So the deficit between each two adjacent monitoring time point would be expressed as a linear function of the karst groundwater level approximately (Figure 2).

$Q j \approx f\left(h^{j}\right)=-A^{t-1} \cdot h^{j+C}, j \in[t-1, t)$

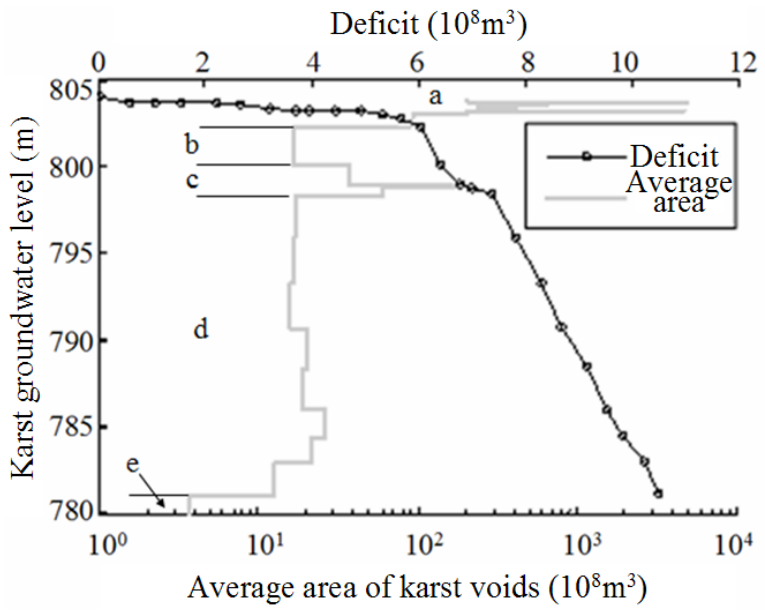

Figure 2 Deficit and average area of void karst voids in vertical direction

\subsection{Spring flow and karst groundwater level}

Predicting the spring flow is difficult, because of the complex flow in karst conduits, heterogeneity of karst aquifers, and the turbulent spring flow. Hydraulic and statistical methods are usually used to predict spring flows ${ }^{[2]}$. Sepúlveda (2009) ${ }^{[3]}$ studied the effects of the hydraulic methods in spring flow predicting. When they are used in karst aquifer, several of the assumptions of the hydraulic equations are violated, the parameters in the equations lose some of their physical basis ${ }^{[3]}$. Other hydraulic methods need detailed information about the karst aquifer (e.g. boundary conditions, porosity, hydraulic conductivity, etc.). However, these information are unavailable for such a large karst groundwater basin ${ }^{[4]}$ Therefore, these methods are not suitable for the well-developed karst aquifer.

In this work, we choose statistical methods to describe the spring flows. The MLR and ANNs are the common statistical methods, but they are lack of the physical bases. A nonlinear regression is used to model the spring flow in the reservoir model. The karst groundwater level is taken as the only direct determinant of the spring flows, because the spring flows have good correlations with the groundwater level. In fact, the groundwater level control the spring flow physically, that provides the statistical method some physical bases, but the method is still an empirical one Other factors, such as rainfall infiltration, well withdrawal, and coal mine drainage, would influence the spring flow indirectly by affecting the groundwater level. The effects of these factors would be embodied in the iteration equations $(9 \sim 11)$

Gaussian functions are employed to build the nonlinear regression models for the Jinci Spring and the Xuan Spring (equation 5, 6, and Table1). And the nonlinear regression models have good agreement with the monitoring data (Figure 3). It shows that $Q^{t} 03$ and $Q^{t} 04$ are monotone increasing with $h^{t}$ in [802.32, 804.00], and [795.94, 804.00], respectively.

$$
Q^{t} 03=a_{1} \cdot \exp \left(-\left(\left(h^{\mathrm{t}}-b_{1}\right) / c_{1}\right)^{2}\right)+a_{2} \cdot \exp \left(-\left(\left(h^{\mathrm{t}}-b_{2}\right) / c_{2}\right)^{2}\right)
$$

$$
Q^{t} 0_{04}=a_{3} \cdot \exp \left(-\left(\left(h^{\mathrm{t}}-b_{3}\right) / c_{3}\right)^{2}\right)+a_{4} \cdot \exp \left(-\left(\left(h^{\mathrm{t}}-b_{4}\right) / c_{4}\right)^{2}\right)
$$

Table 1 Parameters of the nonlinear regression

\begin{tabular}{|c|c|c|c|c|}
\hline Springs & Id & $\mathrm{a}$ & $\mathrm{b}$ & $\mathrm{c}$ \\
\hline \multirow{2}{*}{ Jinci Springs } & 1 & 5.116 & 805.3 & 0.7315 \\
\cline { 2 - 5 } & 2 & 0.5 & 803.7 & 0.6808 \\
\hline \multirow{2}{*}{ Xuan Springs } & 3 & 0.413 & 804 & 0.6128 \\
\cline { 2 - 5 } & 4 & 0.255 & 825.6 & 25.09 \\
\hline
\end{tabular}

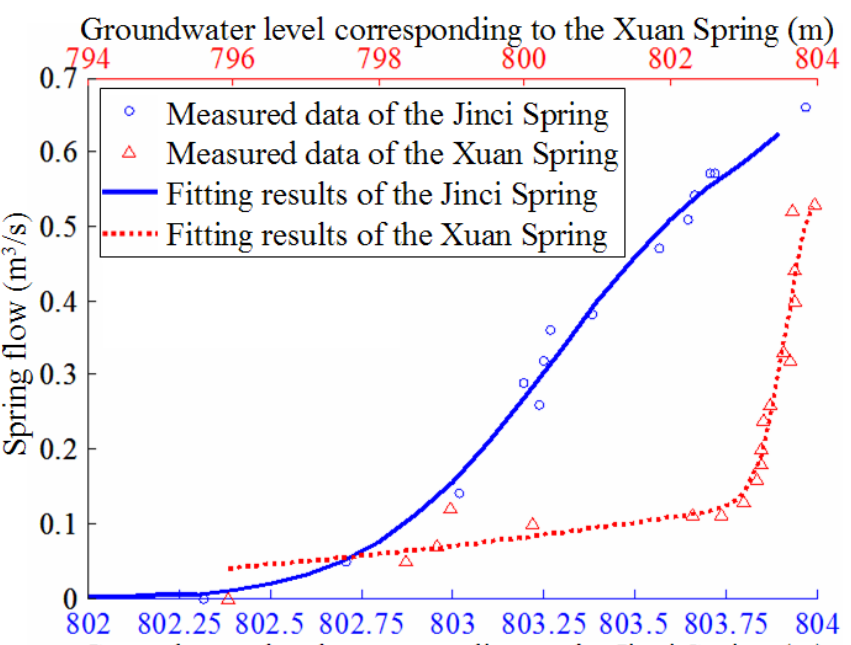

Groundwater level corresponding to the Jinci Spring (m)

Figure 3 Rating curves of the Jinci Spring and the Xuan Spring

\subsection{Lateral discharge and groundwater level}

The lateral discharge is calculated with the Darcy's Law, i.e.

$$
Q_{O 4}^{t}=\sum_{i=1}^{n} q_{i}^{t}=\sum_{i=1}^{n} T_{i} \cdot L_{i} \cdot I_{i}^{t}
$$

Where $n$ is the number of the cross-sections, $q^{t_{i}}$ is the lateral discharge perpendicular to the cross-section $i$ at time point $t . q^{t_{i}}$ is expressed as $q^{t_{i}}=T_{i} \cdot L_{i} \cdot I_{i}$. Where $T_{i}$ is the average transmissivity of porous aquifer on the cross-section $i, L_{i}$ is the length of the cross-section $i$, and $I_{i}$ is the average hydraulic gradient on the cross-section $i$ at the time point $t . I_{i}$ is calculated by $I_{i}=\left(h^{t}-h^{t} 0\right) / L^{0}{ }_{i}$. Where $h^{t}$ is the groundwater level in karst aquifer, $h^{t_{0}}$ is the groundwater level in porous media (we use the same value on each cross-section), $L^{0}{ }_{i}$ is the length between $h^{t}$ and $h^{t}{ }_{0}$ along the groundwater flow direction on each cross-section. When we rewrite equation (7) as equation (8), we could find that $Q^{t} 04$ is a linear function of $h^{t}$, and monotone increasing with $h^{t}$.

$$
Q_{O 4}^{t}=\left(h^{t}-h_{0}^{t}\right) \cdot \sum_{i=1}^{n} T_{i} \cdot L_{i} \cdot I_{i}^{t}
$$


Seven cross-sections along the southeast boundary of the Jinci Spring basin is used to evaluate the later discharge. The cross-section C-D is coincident with the cross-section C'-D' in a plain view. The C-D is a crosssection of the first and second confine aquifers, while the $C^{\prime}-\mathrm{D}^{\prime}$ corresponds to the third and fourth confined aquifers. So are the crosssection D-E and D'-E'. $T_{i}, L_{i}$, and $I_{i}{ }_{i}$ are shown in Table $2 . h^{t}$ is a variable which could be decided with the help of a porous media model.

Table 2 Parameters of the lateral discharges

\begin{tabular}{|c|c|c|c|}
\hline Cross-sections & $\mathrm{L}(\mathrm{m})$ & $\mathrm{T}\left(\mathrm{m}^{2} / \mathrm{d}\right)$ & $\mathrm{L}^{0}(\mathrm{~m})$ \\
\hline A-B & 6000.00 & 69.33 & 517.24 \\
\hline B-C & 9000.00 & 8.64 & 500.00 \\
\hline C-D & 7500.00 & 115.20 & 1500.00 \\
\hline C'-D' $^{\prime}$ & 7500.00 & 122.00 & 1363.64 \\
\hline D-E & 4500.00 & 76.80 & 1500.00 \\
\hline D'-E' $^{\prime}$ & 4500.00 & 180.00 & 1875.00 \\
\hline E-F & 8000.00 & 216.00 & 1500.00 \\
\hline
\end{tabular}

\subsection{Solving water balance equation}

We substitute equation (5), (6) and (8) into equation (3), in order to obtain the karst groundwater level $h^{t}$ at the time point $t$. Then we have iteration equation (9), (10) and (11).

When $h^{t}$ is in [781.12, 795.94), both of the Jinci Spring and Xuan Spring dry up. No spring flow should be considered. Then we have

$Q_{11}^{t}+Q_{12}^{t}+Q_{13}^{t}-Q_{01}^{t}-Q_{02}^{t}-\left(h^{t}-h_{0}^{t}\right) \cdot \sum_{i=1}^{n} T_{i} \cdot L_{i} / L_{i}^{0} \approx f\left(h^{t-1}\right)-f\left(h^{t}\right)(9)$

When $h^{t}$ is in [795.94, 802.32), the Xuan Spring flows out. Then we have

$Q_{I 1}^{t}+Q_{I 2}^{t}+Q_{I 3}^{t}-Q_{O 1}^{t}-Q_{o 2}^{t}-a_{3} \cdot \exp \left(-\left(\left(h^{t}-b_{3}\right) / c_{3}\right)^{2}\right)-$

$a_{4} \cdot \exp \left(-\left(\left(h^{t}-b_{4}\right) / c_{4}\right)^{2}\right)-\left(h^{t}-h_{0}^{t}\right) \cdot \sum_{i=1}^{n} T_{i} \cdot L_{i} / L_{i}^{0} \approx f\left(h^{t-1}\right)-f\left(h^{t}\right)$

When $h^{t}$ is in $[802.32,804.00)$, both the Jinci Spring and the Xuan Spring flow out. Then we have

$$
\begin{aligned}
& Q_{11}^{t}+Q_{12}^{t}+Q_{13}^{t}-Q_{o 1}^{t}-Q_{o 2}^{t}-a_{1} \cdot \exp \left(-\left(\left(h^{t}-b_{1}\right) / c_{1}\right)^{2}\right)- \\
& a_{2} \cdot \exp \left(-\left(\left(h^{t}-b_{2}\right) / c_{2}\right)^{2}\right)-a_{3} \cdot \exp \left(-\left(\left(h^{t}-b_{3}\right) / c_{3}\right)^{2}\right)- \\
& a_{4} \cdot \exp \left(-\left(\left(h^{t}-b_{4}\right) / c_{4}\right)^{2}\right)-\left(h^{t}-h_{0}^{t}\right) \cdot \sum_{i=1}^{n} T_{i} \cdot L_{i} / L_{i}^{0} \approx f\left(h^{t-1}\right)-f\left(h^{t}\right)
\end{aligned}
$$

In equation (9), (10) and (11), $Q^{t_{11}}$ and $Q^{t} t_{12}$ could be determined by the future rainfall data provided by the National Climate Center (NCC) and Pearson III density probability plot, respectively. $Q^{t_{13}} Q^{t}{ }_{01}$ and $Q^{t}{ }_{02}$ could be determined by the exploitation schemes. We have not a verified porous model for porous groundwater in the Taiyuan basin, so we suppose that the $h^{t_{0}}$ is a constant. $h^{t-1}$ is calculated in $t-1$ iteration. Therefore $h^{t}$ is the only unknown quantity in equation (9), (10) and (11).

In order to solve equation (9), (10) and (11), we rewrite them as

$$
\begin{aligned}
& g\left(h^{t}\right)=Q_{11}^{t}+Q_{12}^{t}+Q_{13}^{t}-Q_{o 1}^{t}-Q_{O 2}^{t}- \\
& \left(h^{t}-h_{0}^{t}\right) \cdot \sum_{i=1}^{n} T_{i} \cdot L_{i} / L_{i}^{0}-f\left(h^{t-1}\right)+f\left(h^{t}\right), h^{t} \in[781.12,795.94) \\
& g\left(h^{t}\right)=Q_{11}^{t}+Q_{12}^{t}+Q_{13}^{t}-Q_{o 1}^{t}-Q_{o 2}^{t}- \\
& a_{3} \cdot \exp \left(-\left(\left(h^{t}-b_{3}\right) / c_{3}\right)^{2}\right)-a_{4} \cdot \exp \left(-\left(\left(h^{t}-b_{4}\right) / c_{4}\right)^{2}\right)- \\
& \left(h^{t}-h_{0}^{t}\right) \cdot \sum_{i=1}^{n} T_{i} \cdot L_{i} / L_{i}^{0}-f\left(h^{t-1}\right)+f\left(h^{t}\right), h^{t} \in[795.94,802.32) \\
& g\left(h^{t}\right)=Q_{11}^{t}+Q_{l 2}^{t}+Q_{13}^{t}-Q_{o 1}^{t}-Q_{O 2}^{t}- \\
& a_{1} \cdot \exp \left(-\left(\left(h^{t}-b_{1}\right) / c_{1}\right)^{2}\right)-a_{2} \cdot \exp \left(-\left(\left(h^{t}-b_{2}\right) / c_{2}\right)^{2}\right)- \\
& a_{3} \cdot \exp \left(-\left(\left(h^{t}-b_{3}\right) / c_{3}\right)^{2}\right)-a_{4} \cdot \exp \left(-\left(\left(h^{t}-b_{4}\right) / c_{4}\right)^{2}\right)- \\
& \left(h^{t}-h_{0}^{t}\right) \cdot \sum_{i=1}^{n} T_{i} \cdot L_{i} / L_{i}^{0}-f\left(h^{t-1}\right)+f\left(h^{t}\right), h^{t} \in[802.32,804.00]
\end{aligned}
$$
conservation. The closer $g\left(h^{t}\right)$ approximates to zero, the better the solving effect is. Moreover, the $g\left(h^{t}\right)$ getting close to zero means that the deficit is close to the difference of recharge and discharge, so there is no water being created or consumed in the reservoir model. In the verification and prediction periods, $g\left(h^{t}\right)$ is less than $10^{-3}$, so the model follows the mass conservation approximately

\subsection{Heterogeneity of the kast aquifer}

The deficit and the average area of the karst voids show the heterogeneity of the kast aquifer to some extent. Equation (2) shows that the deficit 
corresponding to $\Delta h^{t}$ equals to the volume of water yield by karst voids. The proportion of deficit to the volume of kast aquifer corresponding to $\Delta h^{t}$ approximates the effective porosity which can be expressed as a proportion of the average area of the karst voids to the average area of the karst aquifer corresponding to $\Delta h^{t}$ approximately. So the deficit or the average area of the karst voids could show the vertical heterogeneity of the kast aquifer. And that makes the reservoir model characterized as a lumped model be equipped with some character of distributed model. The karst becomes undeveloped gradually with the increment of the depth (Figure 2). The developed extent could be divided into 5 degrees (a e in Figure 2). The degree a is inaccuracy, because the average area of karst voids exceeds the area of the Jinci Spring basin (about $2430 \mathrm{~km}^{2}$ ).

\section{Conclusion}

This paper is aimed at building a reservoir model is built to characterize the functioning of the karst aquifer of the Jinci Spring based on the data of recharge, discharge and groundwater level during the long term depletion-type extraction. The model is verified with rainfall infiltration, Fen River leakage, well withdrawal, coal mine drainage, spring flow and lateral discharge, karst groundwater level and deficit from 1981 to 2006. The vital step in this work is building the relationship between deficit and the karst groundwater level. In the step, the vertical heterogeneity of karst aquifer is detected by the deficit increment which varies with the karst groundwater level. The volume of the reservoir model based on the deficit has similarity with the volume of the voids in the karst aquifer. That endows the lumped reservoir model characterized with some characters of distributed model in vertical direction, so the model could give satisfactory results within the measure data. However, if the karst groundwater level exceeds the measure data, the model can only give a result by extrapolation which could not be accurate.
The reservoir model could be used to model the recovery of spring flow karst groundwater level and deficit, at an annual time scale. Well withdrawal, coal mine drainage, and artificial recharge are set in the model, so it could be used in macroscopic groundwater resources management. The modeling results at a daily time scale are based on more dentil information of the epikarstic zone and the physical process of the Fen River leakage. The information is not available at present, so it is not tested that the performance of the model at a smaller time scale.

\section{Acknowledgements}

The acknowledgement for the National Natural Science Foundation of China (Grants No. 51409161, No. 51509157), the Natural Science Foundation of Jiangsu Province (Grants No. BK20140080).

\section{References}

[1]J. Wu. "Groundwater exploitation in China at the beginning of the 21th century". China Waterpower Press, (2004).

[2]C. Hu, Y. Hao, T. Yeh, B. Pang, Z. Wu. "Simulation of spring flows from a karst aquifer with an artificial neural network",Hydrological Processes, 22 pp. 596-604, (2008).

[3]N. Sepúlveda. "Analysis of methods to estimate spring flows in a karst aquifer",Ground Water, 47, pp. 337-349, (2009).

[4]B. Majone, A. Bellina, A. Borsatob. "Runoff Generatio $\mathrm{n}$ in karst catchments: multifractal analysis",Journal of Hydrology, 294, pp. 176-195, (2004).

[5]R. L. Burden, J. D. Faires. "Numerical analysis”, Brooks/Cole Publishing Company, (2000). 